\title{
Linearity versus Cross-Talk: Biological Models and the Role of the Society for Pediatric Research in the 21st Century
}

\author{
DANIEL BERNSTEIN
}

Stanford University, Palo Alto, CA 94304, U.S.A.

Nearly 75 y ago, a group of young pediatric scientists broke ranks with the American Pediatric Society and formed the nucleus for what would become the Society for Pediatric Research (SPR). Their goal was to provide an opportunity for young pediatric investigators to present their work at an annual forum. Few would argue that over the ensuing years, the SPR, along with the annual Pediatric Academic Societies meeting, has not only served but also far exceeded the goals of that group of young investigators back in 1929. However, pediatric science and academic medicine have undergone profound changes during this same time period, with some of the most significant changes occurring in the last decade. For those of us engaged in pediatric research in the 21 st century, we should be asking, "Is the SPR still relevant, and what role should the organization play in our academic careers?"

To answer this question, I would like to explore a few examples of how our paradigms for modeling biologic systems have changed dramatically over the past decade, how these paradigm shifts in science have had profound implications for scientists themselves, and how these shifts will influence the training and career options of the pediatric researcher of the future.

Science is replete with examples where we have developed models of physical or biologic processes and then naively presumed that we fully understood their basic mechanisms. In nearly every case, once new tools were developed to refine our measurements, improving the strength of our particle accelerators, the resolution of our microscopes, or the reach of our telescopes, we have uncovered finer levels of structure and additional layers of complexity. Sometimes we learn that old hypotheses, proven incorrect under one scientific model, develop newfound relevance in the context of new observations.

At the turn of the 20th century, physicists lived in a world governed by the orderly and highly linear system of Newtonian mechanics. In the year 1900, one of the great minds of physics, Lord Kelvin, proclaimed: "There is nothing new to be discovered in physics now. All that remains is more and more precise measurement." (1) Yet, in barely $5 \mathrm{y}$, the world of Newtonian

Correspondence: Daniel Bernstein, M.D., Department of Pediatrics, Stanford University, 750 Welch Road, Suite 305, Palo Alto, CA 94304, U.S.A.; e-mail: danb@stanford.edu

Presented at the 2003 Annual Meeting of the Pediatric Academic Societies, Seattle, Washington, U.S.A.

DOI: 10.1203/01.PDR.0000132661.55523.BF mechanics was turned upside down by a new and highly complex paradigm for modeling our physical world. In the heady, early days of molecular biology, many pioneers in the field were equally convinced that the central questions of molecular biology would be easily answered well before the end of the 20th century.

\section{LINEARITY VERSUS CROSS-TALK AND THE GENETIC CODE}

This year marks the 50th anniversary of the description of the double helical structure of DNA. Given subsequent events, it may be hard to remember that at the time of Watson and Crick's landmark publication, there were still many in the scientific community who believed that proteins, and not nucleic acids, were responsible for carrying genetic information. In a paper published in Nature barely 2 mo afterward, proponents of the protein hypothesis argued that "the gene is essentially an abstract idea" and that "it may be a mistake to try to clothe this idea in a coat of nucleic acid" $(2,3)$.

The revolution that began in 1953 resulted in the development of a new model, which came to be known as the central dogma. This model proposed that the flow of genetic information was unidirectional and linear: DNA carries the genetic programming; RNA functions only to shuttle this information to the cytoplasm; and proteins carry out the structural and functional roles in the cell. In this model, common genetic variations are essentially binary: the substitution of a single base, A for G, or C for T (4). This model resonated particularly well in an era when digital computing was also coming of age. Over the intervening years, this model grew in complexity, as multiple layers of transcriptional activators and repressors and their DNA binding sites were described. Despite these additions, the basic linear nature of the model was preserved. However, it soon began to be recognized that the networks of transcription factors and DNA binding sites might play at least as important a role as the code within DNA itself.

The old linear models could not fully explain several new findings, such as genetic imprinting, in which the expression of a gene depends on the parent from which it is derived. An example of mammalian imprinting is seen in the pattern of inheritance of the gene encoding IGF2, which is expressed only from the paternal allele (5). Imprinting may have important implications in genetic diseases, such as BeckwithWiedemann, Prader-Willi, and Angelman syndromes, and in 
carcinogenesis, as loss of imprinting of the IGF2 gene has been implicated in the development of colorectal cancer (5). Imprinting is but one example of the phenomenon of epigenetics, where changes in gene expression can be transmitted across at least one generation but are not related to changes in DNA (6).

It now appears that proteins, once thought to be the carriers of genetic information and then relegated to a back seat after the ascendancy of DNA, may play a much more substantial role in genetic regulation than ever before realized. Although the primary structure of the histones was first described in 1974, for the next two decades, their function was relegated to mere structural support for DNA (Fig. 1). However, starting in the late 1990s, we began to recognize that proteins, by adding and removing acetyl, methyl, and phosphate groups, interact with histones and alter their morphology, either hiding or uncovering regions of DNA for gene transcription (7). These revelations have led some to argue that there is a second layer of genetic code altogether, the "histone code," which may be as complex and ultimately as important for the passage of information between generations as the code contained within DNA itself (8).

We are now learning of exciting new levels of crossregulation from places least expected. For decades, RNA was considered, as described by one pioneer in the field, a "rather dull molecule." Recently, evidence has emerged that a class of RNA molecules called small RNAs also play a role in the regulation of genetic information. Small RNAs can alter gene expression and in some species literally shape the entire genome.

Evidence that RNA might play more than a messenger role first arose in the mid-1990s. Researchers attempting to use antisense RNA to block gene expression were surprised to find that both antisense and sense RNA preparations resulted in similar levels of interference (9). The mystery of this lack of strand specificity deepened with the discovery that doublestranded RNA was even more potent in suppressing gene expression, a process subsequently dubbed "RNA interference" $(9,10)$. The discovery this past year of active cellular systems that regulate RNA interference imply that it has a natural genetic regulatory function (Fig. 2). An enzyme, appropriately dubbed "Dicer" was identified which is responsible

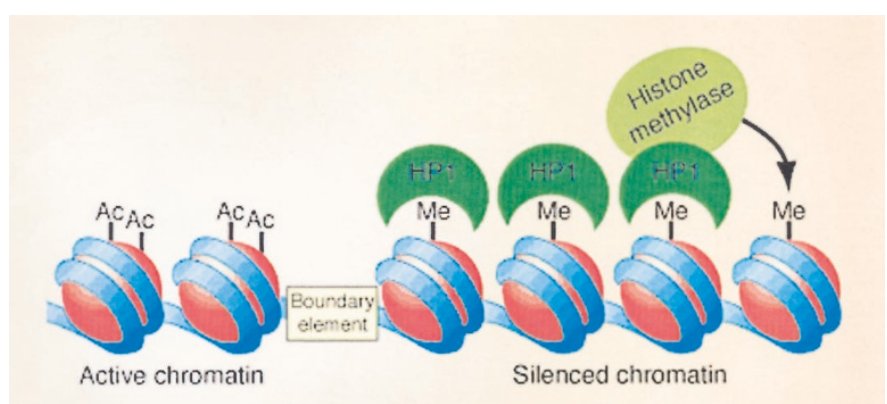

Figure 1. Modification of histones by histone methylase and other proteins either silences or uncovers regions of DNA for gene transcription. This "histone code" may be as important for the passage of genetic information as the code contained within DNA. Reprinted with permission from Pennisi E 2001 Behind the scenes of gene expression. Science 293:1064-1067.

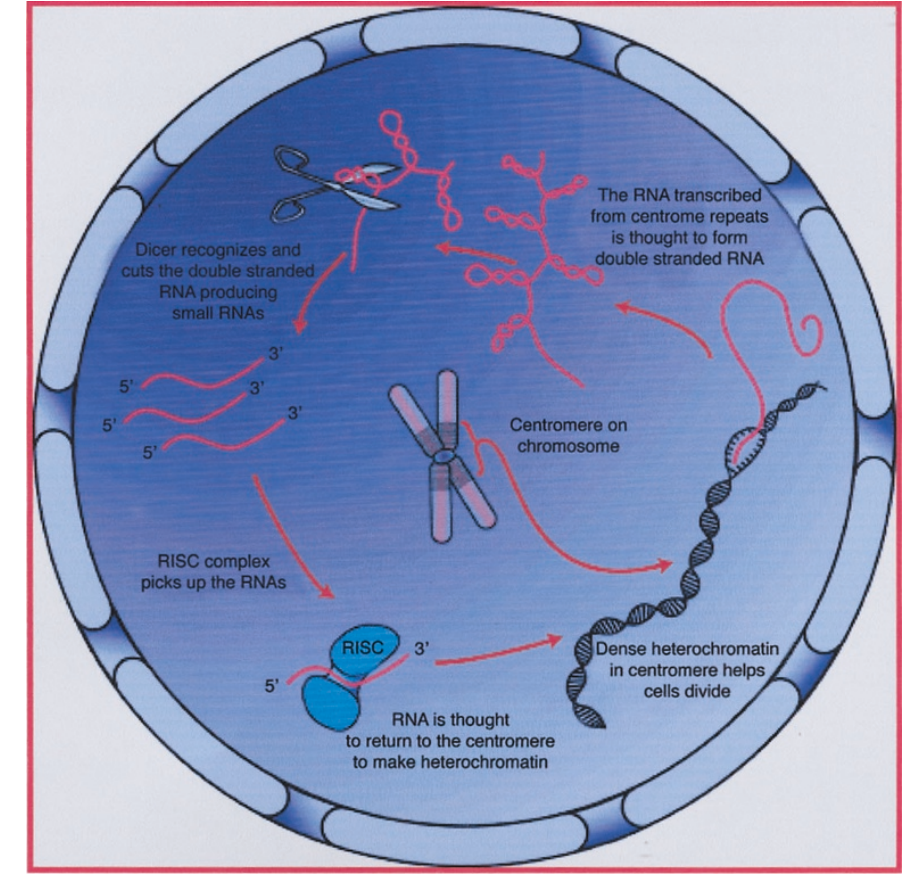

Figure 2. Double-stranded RNA is cleaved into 21-23 nucleotide fragments by the enzyme dicer. These short interfering RNAs are delivered to a complex known as RISC and then pair with and degrade messenger RNAs with complimentary sequences. Reprinted with permission from Couzin J 2002 Breakthrough of the year: small RNAs make a big splash. Science 298:22962297. Copyright 2002 American Association for the Advancement of Science

for processing double-stranded RNA intracellularly into 21-23 nucleotide fragments (11). These small RNAs, known as short interfering RNAs, are delivered to a complex called RISC, which uses the sequence information of the small RNAs to pair with and then degrade messenger RNAs with complimentary sequences (9).

One of the most exciting discoveries from the world of RNA interference is the role that small RNAs play in epigenetic regulation. As mentioned earlier, one of the mechanisms for epigenetic inheritance is mediated via changes in the conformation of chromatin complexes. Some species of doublestranded RNA are transcribed from chromosomal centromere repeats, which are then processed into small RNAs, which together with RISC alter the degree of compaction of heterochromatin complexes and thus influence gene expression (9). This process of RNA interference may not only play a key role in genetic and epigenetic regulation but may become a valuable tool for the production of genetically altered animals. Several labs have used RNA interference to silence gene expression, a process known as gene knockdown (9).

Before the human genome project, predictions for the number of human genes encoded by the $\sim 3$ billion base pairs ranged as high as $100,000-200,000$. It was thus surprising to manyand perhaps a bit humbling - that the actual number of human genes is probably as low as 30,000-40,000 (Table 1). How can a multicellular organism as complex as a human, with all its cell and tissue types and functions, have only $30 \%$ more genes than the simple roundworm? The answer may lie in a model of gene regulation which is rich and complex with cross-talk between proteins and nucleic acids, adding considerable 
Table 1. Comparison of the estimated number of genes of various organisms

\begin{tabular}{|c|c|c|c|c|}
\hline Organism & Estimated size & $\begin{array}{c}\text { Estimated gene } \\
\text { number }\end{array}$ & Average gene density & $\begin{array}{c}\text { Chromosome } \\
\text { number }\end{array}$ \\
\hline Homo sapiens (human) & 3000 millionbases & $\sim 30000$ & 1 gene per 100000 bases & 46 \\
\hline Mus musculus (mouse) & 3000 millionbases & $\sim 30000$ & 1 gene per 100000 bases & 40 \\
\hline Arabidopsis thaliana (plant) & 125 millionbases & 25500 & 1 gene per 4000 bases & 5 \\
\hline Caenorhabditis elegans (roundworm) & 97 millionbases & 19100 & 1 gene per 5000 bases & 6 \\
\hline Saccharomyces cerevisiae (yeast) & 12 millionbases & 6300 & 1 gene per 2000 bases & 16 \\
\hline
\end{tabular}

Before completion of the Human Genome Project, initial predictions for the number of human genes had ranged as high as $100000-200000$.

breadth and depth to the information provided by those 30,000 genes. In this model, proteins and RNA are responsible not only for fine-tuning gene activity but for mediating changes in developmental programs that ultimately help to distinguish one entire species from another.

\section{LINEARITY VERSUS CROSS-TALK AND CELL SIGNALING}

From the world of cell signaling comes another example of how the modeling of cellular processes has undergone a paradigm shift. Until quite recently, the classic models for cell signaling were linear sequences of interactions progressing toward a limited set of cell responses. In the example illustrated in Fig. 3A, the hormone epinephrine binds to its cell surface receptor, the $\beta$-adrenergic receptor, which activates the stimulatory $\mathrm{G}$ protein, Gs, which activates adenylyl cyclase. Through a cascade of posttranslational modification of downstream effectors, cell function is altered. In this classic model, little attention was paid to communication between different signal transduction cascades. Although the concept of crosstalk between signaling pathways was first advanced as early as 1980, it was not taken seriously.

Subsequent models of G-protein-coupled receptor signaling have grown tremendously in their complexity. In the mid1990 s, evidence emerged that there were conditions under which $\beta$-receptors could signal not only through the stimulatory $\mathrm{G}$ protein but through the inhibitory $\mathrm{G}$ protein, $\mathrm{Gi}$, as well (Fig. $3 B$ ) (12). Under these conditions, agonist stimulation of the receptor recruits to the cell membrane a protein complex containing a mitogen-activated protein kinase module. Activation of this mitogen-activated protein kinase pathway leads to alterations not in cell function but in cell structure $(13,14)$. Thus, adrenergic stimulation plays a more complex role than previously appreciated, resulting in both short-term functional and long-term structural changes in the cell.

Just how deep do these layers of complexity go? Over the last few years, data have emerged suggesting that each signaling cascade modulates multiple others and that this modulation occurs at multiple levels. Figure 4 summarizes experimentally demonstrated cross-talk between four well-described signaling pathways reported in the literature over just a 2-y period (15). Quoting Jacques Dumont: "Considering the multiple theoretical kinetic consequences ... the possible implications in terms of cell behavior are staggering" (15). With four signaling pathways of five steps each, there are a total of 760 possible positive and negative interactions. However, this new "simple view" that "everything does everything to everything" is difficult to reconcile with the known specificity of signaling action in cells and living organisms under physiologic conditions.

It is clear that many of these reported cross-talk pathways may not occur in cells under normal physiologic conditions and that some may be artifacts of the experimental system used. Since protein interactions are difficult to study at low concentrations, researchers use transfection techniques to increase expression of a protein of interest, often by 100 -fold or more. At this level of overexpression, weak nonphysiologic interactions may be amplified, and interactions which would normally be precluded by intracellular compartmentalization may occur. On the other hand, many interactions may only occur in cells at a critical time during development, and these may be overlooked because of the artificial conditions of cell culture. This last concern is of particular relevance to those of us involved in pediatric research, as developmental differences in cellular interactions are crucial to understanding the processes of cellular differentiation and embryogenesis.

Thus, to demonstrate the physiologic relevance of these multiple signaling interactions, researchers must move beyond isolated cell systems and reconfirm their results in whole organs, in experimental animals, and, ultimately, in humans. These interactions require a different type of cross-talk, that between protein chemists, molecular biologists, physiologists, bioengineers, and physicians.

\section{EVOLVING MODELS OF ACADEMIC MEDICINE: THE SCIENCE MOLDS THE SCIENTIST}

Just as the linear models of DNA transcription and transmembrane cell signaling held sway for much of the past century, linear models were also the norm for the academic enterprise (Fig. 5A). The hallmark of success for the young physician scientist was independence. Collaborations most often occurred within a laboratory or division, occasionally across departments, and rarely across schools. The last decade has seen a paradigm shift in the model of academic medicine from a linear one to one that is highly collaborative, extensively interactive, and evocative of the cross-talk of the biologic pathways that we study. Initially, this model shift was largely limited to within the confines of the medical school. However, more recently, this cross-talk has spread between schools within the university (Fig. 5B). Many universities are 

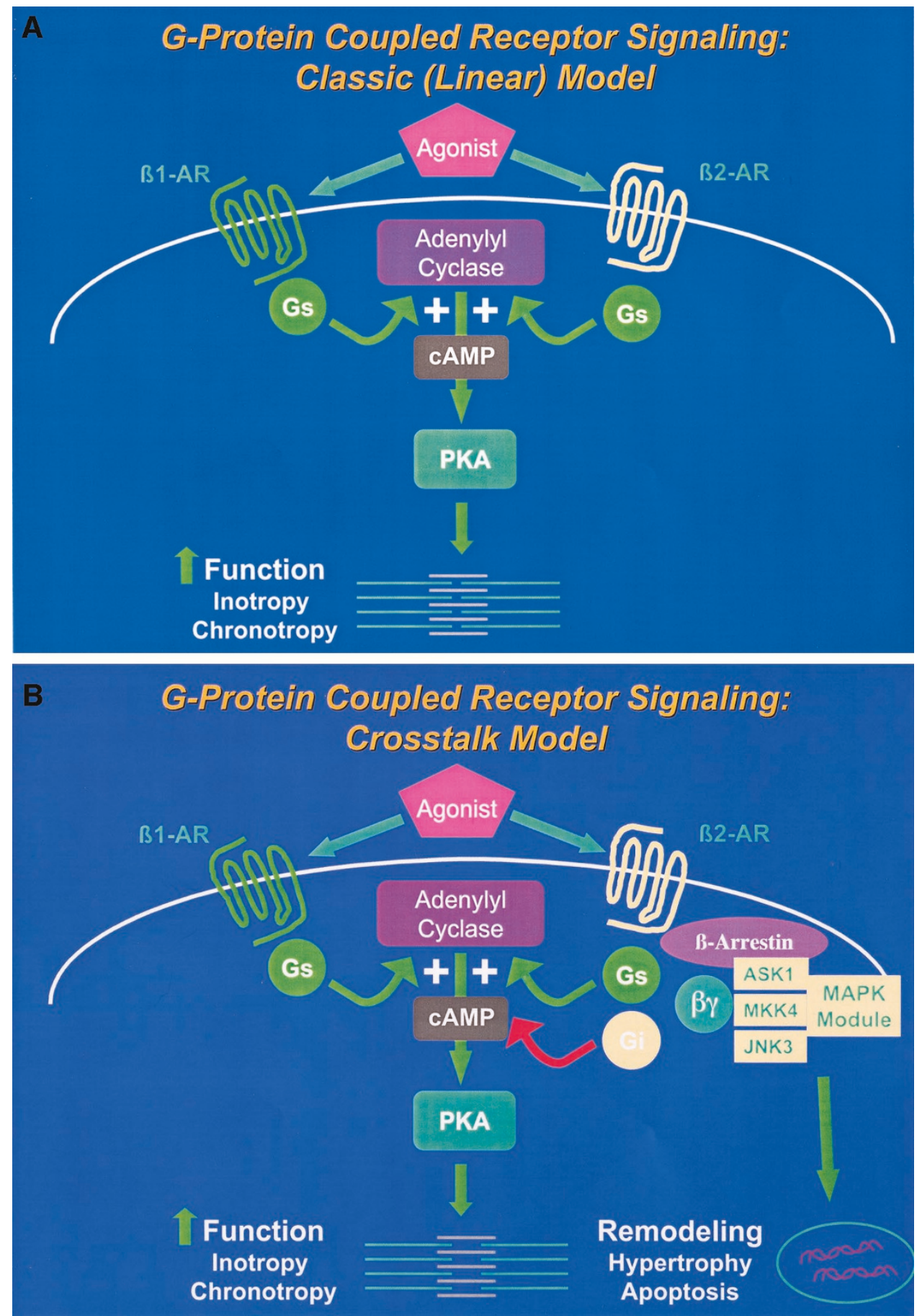

Figure 3. (A) The classic (linear) model of $\mathrm{G}$ protein-coupled receptor signaling. A hormone agonist binds to the receptor, activating the stimulatory $\mathrm{G}$ protein (Gs), which activates adenylyl cyclase. Through phosphorylation of a series of downstream effectors, cellular function, in this example cardiac contraction, is altered. $(B)$ New cross-talk model of $\mathrm{G}$ protein-coupled receptor signaling. Recent evidence demonstrates that $\beta 2$-adrenergic receptors can also couple to the inhibitory $\mathrm{G}$ protein $(\mathrm{Gi})$. Under certain conditions, $\beta 2$-receptor stimulation can activate a mitogen-activated protein kinase cascade, leading to alterations not in cell function but in cell structure.

establishing institutes which transcend traditional departments and schools. These institutes, if given the proper resources of space, faculty billets, and targeted fundraising, can provide the nexus for the career development of future pediatric researchers.

One of the most prominent examples of this intra-university cross-talk is the emerging field of bioengineering. For years, biologists have struggled to improve the fidelity of tissue culture for studying organ function and enhancing drug development. Collaborating with tissue engineers, physician scientists are building bioreactors containing miniaturized organ systems, such as the liver chip being developed by researchers at MIT. These chips allow co-culture of different cell types, such as hepatocytes and endothelial cells, as well as the application of mechanical shear stress to better simulate in vivo conditions (16). Tissue-engineered heart valves are being de- 


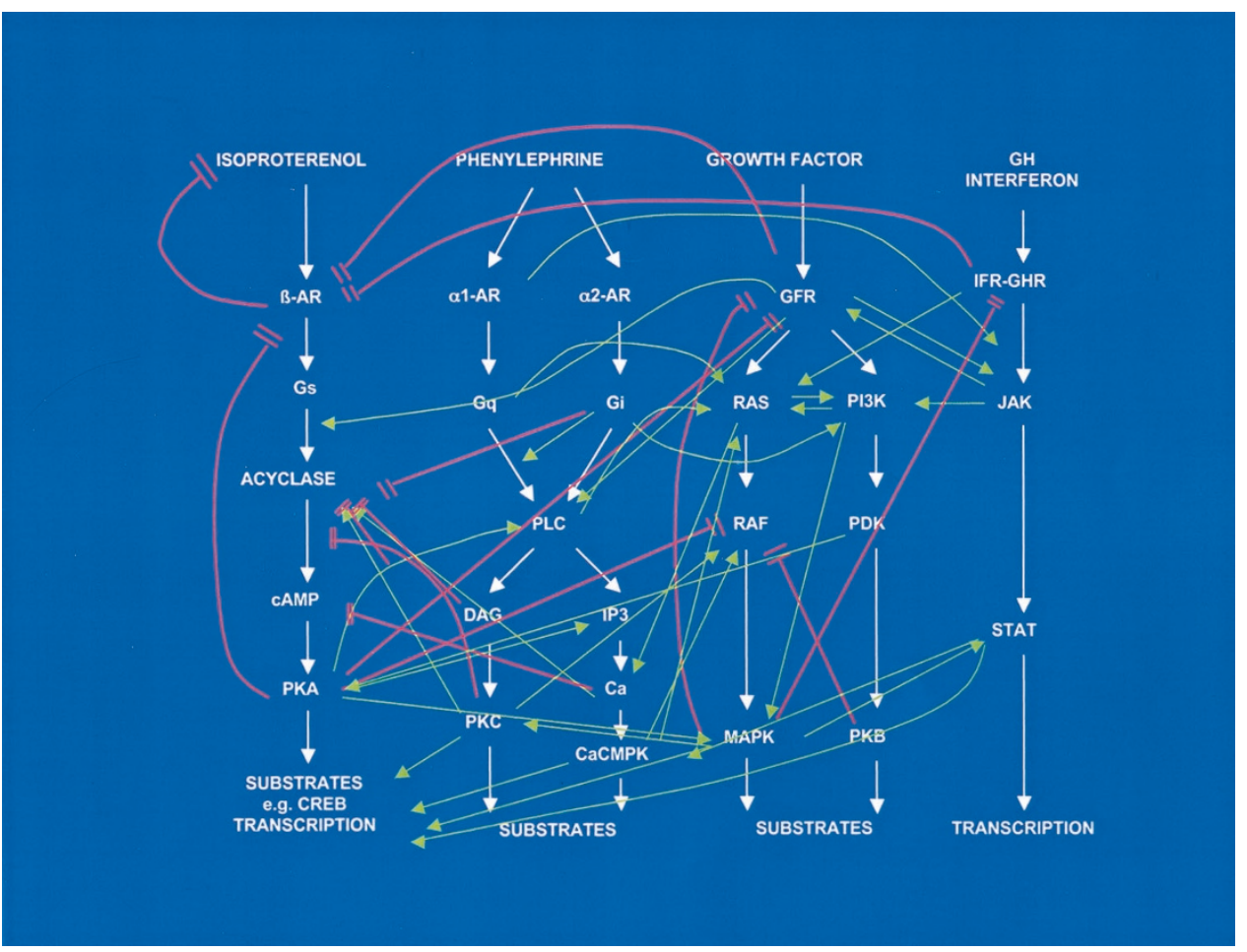

Figure 4. Experimentally demonstrated cross-talk between four common signaling pathways. With four signaling pathways of five steps each, there are a total of 760 possible positive and negative interactions. Adapted from Dumont JE, Pécasse F, Maenhaut C 2001 Crosstalk and specificity in signalling. Are we crosstalking ourselves into general confusion? Cell Signal 13:457-463. Copyright 2001, with permission from Elsevier.

rived from myofibroblasts and endothelial cells harvested from peripheral arteries and veins and grown in culture on special bioabsorbable polymer scaffolds (17). Unlike current homograft or xenograft valves, these engineered valves are living tissue and have the potential for growth, avoiding the need for multiple replacements as children grow. Computer scientists, working in concert with radiologists, have ushered in a new era of noninvasive body imaging, building three- and fourdimensional models. Finally, were it not for advances in bioinformatics, the human genome project could never have been accomplished. Consider that three billion letters, if printed, would fill 200 major city telephone books. Using the information contained within this massive database would be impossible were it not for the advances in computing which have enabled researchers easy access with the click of a mouse. As we move into the field of proteomics, even more powerful biocomputing resources will be required.

\section{THE SPR AS A MODEL FOR ACADEMIC CROSS-TALK}

How, then, does all this relate to the question at hand? Is the SPR relevant for 21 st century academic pediatricians? For an organization to effectively meet the present and future challenges of academic pediatrics, that organization must have the capacity to change as new challenges and new opportunities arise, just as our models of biologic systems have changed. I will argue that the SPR has risen to meet these challenges and is the organization which is capable of providing the cross-talk required for pediatric researchers to be successful in 21 st century pediatric investigation. Let us examine several examples.
Membership. Seven years ago, facing a declining membership, the society undertook a strategic planning process, reviewing membership criteria and, by so doing, debating the essence of what it meant to be a member of the society. Recognizing the longer length of academic training and the increasing age at which new members were inaugurated into the society, fundamental changes were made, including an increase in the age of active membership. The society removed often-arbitrary barricades to membership based on controversial definitions of independence, recognizing the collaborative nature of the present research environment. Last year, recognizing the growing contributions of the international pediatric scientific community, the SPR extended active membership to pediatric researchers from all nations. At this year's PAS meeting, the Society began deliberating new initiatives to further reach out to our international colleagues and foster worldwide collaboration in research for the benefit of children. The success of these initiatives can be measured by the increase in active membership in the society and the phenomenal growth in attendance at the PAS meeting.

Alliance organizations. The SPR has been dubbed the "big tent" for pediatric academic organizations. Five pediatric subspecialty societies and two additional alliance organizations now hold their annual meetings in conjunction with the PAS meeting, enhancing the potential for cross-specialty collaboration (Table 2). One of the immediate and exciting benefits of these new alliances has been to invigorate the meeting with state-of-the-art symposia jointly sponsored by two or more societies. In what other forum can researchers interested in a topic such as ischemia-reperfusion injury 
A

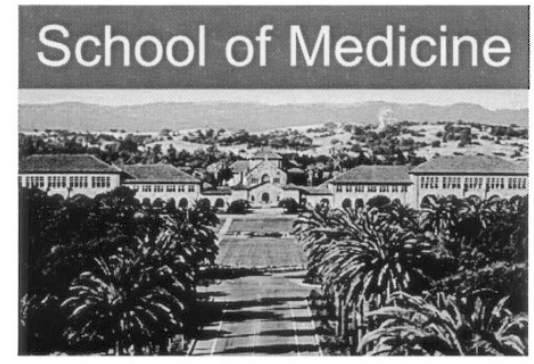

Department Chair

Division Chief/Laboratory Director

Co-Investigator Young Investigator Co-Investigator

Fellows and Students

B

Institutes/Centers of Excellence
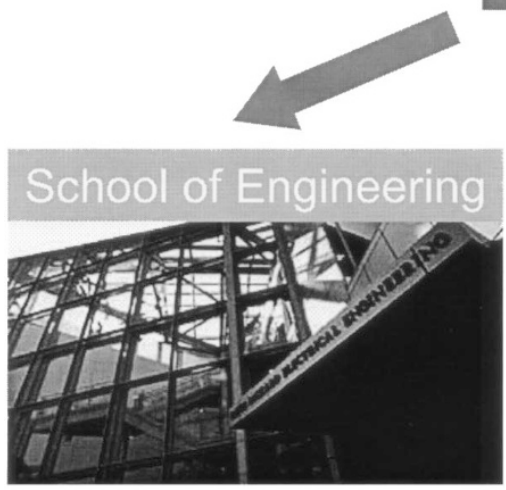

Nentor

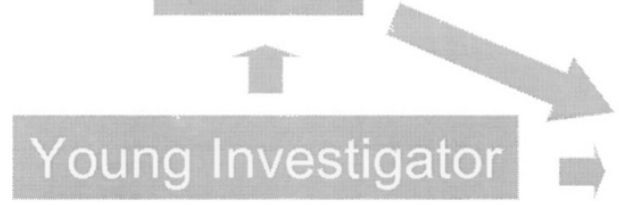

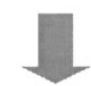
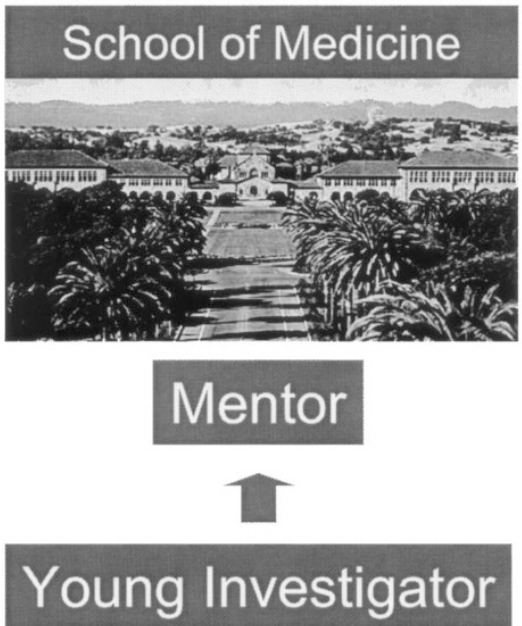
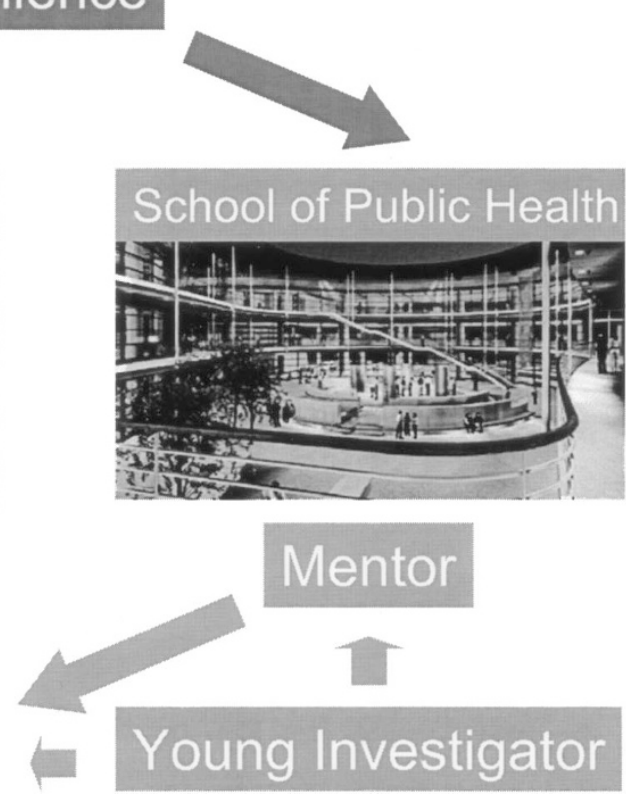

Figure 5. (A) As was true for many fields of science, the linear models for academic enterprise were also the norm for much of the past century. (B) the last decade has seen a paradigm shift in the model of academic medicine from a linear one to one that is highly collaborative, extensively interactive, and evocative of the cross-talk of the biological pathways that we study.

in children find a plenary session with presentations by leading cardiologists, nephrologists, and neurologists, among them clinicians, clinician-scientists, and basic scien- tists? The SPR represents the only venue today for regular ongoing cross-talk between pediatric scientists of all subspecialties. 
Table 2. Alliance organizations of the Pediatric Academic Societies annual meeting

ASPH/O (Hematology-Oncology)

ASPN (Nephrology)

Lawson-Wilkins Society (Endocrinology)

Pediatric Infections Disease Society

Society for Developmental Pediatrics

Association of Pediatric Program Directors

March of Dimes Prize in Developmental Biology

The future of academic pediatrics. One of the major challenges facing academic pediatrics is the education of future physician-scientists. Translational research will be more complex and require participants to speak the language of basic science as well as the language of clinical pediatrics. With declining reimbursements and the higher acuity of pediatric subspecialty medicine, clinical commitments will be greater, yet the future availability of well-trained clinician scientists is uncertain. One of the major initiatives to address changes in pediatric education is the Future of Pediatric Education, or FOPE II, report. Implementation of the recommendations in this report will be directed through the Pediatric Education Steering Committee of the Federation of Pediatric Organizations of which the SPR is a member. This cross-talk between pediatric organizations is vital to the future of academic pediatrics. SPR participation in this process will provide important input regarding the training of future academic pediatricians, not from department chairs or senior scientists but from those who are closest to the front lines. Since FOPE I, there has been a shift in pediatric education to a more linear model, with a heavy focus on primary care pediatrics. We must raise our voice in support of changes in pediatric training that will provide residents increased exposure to faculty role models from the worlds of clinical and basic science. We must give residents the opportunity to experience the challenges and rewards of a subspecialty-based academic career. We must shift the model of residency training from linearity to cross-talk.

Finally, as the American Board of Pediatrics debates the research requirement for fellows and explores the development of a research fast track, we must continue to advocate that "the principal goal of fellowship training should be the development of future academic pediatricians" and that fellows "should be selected on the basis of their level of commitment to attainment of adequate research training and to a career in academic pediatrics as a physician scientist" (18). Above all, the SPR remains the sole organization dedicated to giving center stage to the contributions of the young investigator, stimulating the development of new ideas, challenging old dogma, and enhancing cross-talk between generations of scientists.

Strategic planning. This year, the SPR Council approved a recommendation to establish a strategic planning committee which will examine the role of the organization over the next decade. One of the many charges presented to this committee was to evaluate how the SPR can encourage the development of a new subspecialty section on bioengineering applications in pediatric science and integrate that section into the annual meetings. Other important charges to this committee will include a reexamination of membership criteria and development of a special interest group in outcomes research.

Public Policy Council. Another medium where the SPR provides valuable opportunities for cross-talk is the Public Policy Council. A joint initiative of the APS, SPR, and the Association of Medical School Pediatric Department Chairs, the Public Policy Council has for years been the voice of the SPR in Washington on legislative initiatives concerning academic pediatrics and pediatric research. Chaired by Dr. Myron Genel, the Public Policy Council has provided important input into key areas such as the FDA's suspension of the pediatric rule, stem cell research, children as research subjects, HIPAA regulations, and the level of National Institutes of Health research appropriations, among many others. This year, in recognition for the important role he has played in advancing the SPR's agenda in public policy, Dr. Genel was presented with the SPR Distinguished Service Award. Through its participation in the Public Policy Council, the SPR participates in cross-talk with policy makers to guarantee funding for vital children's research programs.

Through these initiatives, the SPR has moved into the $21 \mathrm{st}$ century as a vibrant society with a growing and increasingly active membership. The society will continue to fulfill its primary goal, set years ago by those pioneer members, to provide a forum for the presentation of research by young pediatric investigators. However, the society will also serve an increasing leadership role in forwarding the national (and international) agenda for pediatric research by promoting interactions, collaborations, and cross-specialty networking in a way that no other society can.

\section{REFERENCES}

1. Weisstein EW Kelvin, Lord William Thompson (1824-1907). http://scienceworld.wolfram.com/biography/Kelvin/html

2. Campbell PN, Work TS 1953 Biosynthesis of proteins. Nature 171:997-1001

3. Olby R 2003 Quiet debut for the double helix. Nature 421:402-405

4. Hood L, Galas D 2003 The digital code of DNA. Nature 421:444-448

5. Falls J, Pulford D, Wylie A, Jirtle R 1999 Genomic imprinting: implications for human disease. Am J Pathol 154:635-647

6. Wolffe A, Matzke M 1999 Epigenetics: regulation through repression. Science 286:481-486

7. Felsenfeld G, Groudine M 2003 Controlling the double helix. Nature 421:448-453

8. Jenuwein T, Allis CD 2001 Translating the histone code. Science 293:1074-1080

9. McManus M, Sharp P 2002 Gene silencing in mammals by small interfering RNAs. Nat Rev Genet 3:737-747

10. Fire A, Xu S, Montgomery MK, Kostas SA, Driver SE, Mello CC 1998 Potent and specific genetic interference by double-stranded RNA in Caenorhabditis elegans. Nature 391:806-811

11. Bernstein E, Caudy AA, Hammond SM, Hannon GJ 2001 Role for a bidentate ribonuclease in the initiation step of RNA interference. Nature 409:363-366

12. Xiao R-P, Ji X, Lakatta E 1995 Functional coupling of the $\beta 2$-adrenoceptor to a pertussis toxin-sensitive $G$ protein in cardiac myocytes. Mol Pharmacol 47:322-329

13. Luttrell L, Gerguson S, Daaka Y, Miller W, Maudsley S, Della Rocca G, Lin F-T, Kawakatsu H, Owada K, Luttrell D, Caron M, Lefkowitz R $1999 \beta$-arrestindependent formation of $\beta 2$-adrenergic receptor-Src protein kinase complexes. Science 283:655-661

14. Daaka Y, Luttrell L, Lefkowitz R 1997 Switching of the coupling of the $\beta 2$ adrenergic receptor to different $G$ proteins by protein kinase A. Nature 390:88-91

15. Dumont JE, Pécasse F, Maenhaut C 2001 Crosstalk and specificity in signalling. Are we crosstalking ourselves into general confusion? Cell Signal 13:457-463

16. Powers M, Domansky K, Kaazempur-Mofrad M, Kalezi A, Capitano A, Upadhyaya A, Kurzawski P, Wack K, Stolz D, Kamm R, Griffith L 2002 A microfabricated array bioreactor for perfused 3D liver culture. Biotechnol Bioeng 78:257-269

17. Hoerstrup S, Sodian R, Daebritz S, Wang J, Bacha E, Martin D, Moran A, Guleserian K, Sperling J, Kaushal S, Vacanti J, Schoen F, Mayer J 2000 Functional living trileaflet heart valves grown in vitro. Circulation 102(suppl 3):III-44-III-49

18. American Board of Pediatrics 2002 Federation of Pediatric Organizations Statement on Pediatric Fellowship Training. In: Annual Report of the American Board of Pediatrics to the Nominating Societies. American Board of Pediatrics, Chapel Hill, NC 